\title{
Occurrence of Polycyclic Aromatic Hydrocarbons (PAHs) in Beached Plastic Pellets from Mumbai Coast, India
}

\author{
H.B. Jayasiri ${ }^{1 *}$, C.S. Purushothaman ${ }^{2}$ and A. Vennila ${ }^{2}$ \\ ${ }^{1}$ National Institute of Oceanography and Marine Sciences, National Aquatic Resources, Research \\ and Development Agency, Crow Island, Colombo 15, Sri Lanka \\ ${ }^{2}$ Aquatic Environment and Health Management Division, Central Institute of Fisheries \\ Education, Panch Marg, Versova, Mumbai, 400 061, India
}

Date Received: 04-10-2013 Date Accepted: 20-01-2014

\begin{abstract}
PAHs are a class of ubiquitous pollutants which consist of two or more fused benzene rings in various arrangements. A number of PAH compounds are known carcinogens and bioaccumulate and biomagnify. These compounds originate naturally as well as anthropogenically through oil spills, incineration of waste and combustion of fossil fuels and wood. The environmental consequence of plastic pellets is the sorption of organic pollutants on their surface from the sea surface microlayer (SML) where the hydrophobic contaminants are known to be enriched. The plastic pellets were collected along the recent high tide line from four beaches of Mumbai coast bimonthly during May 2011 and March 2012. A total of 72 pools of plastic pellets were extracted, fractionated and analysed by gas chromatograph coupled to a mass spectrometer to evaluate the extent and sources of 16 PAHs. The mean $\Sigma \mathrm{PAH}$ concentration in pellets was $9,202.30 \pm 114.89 \mathrm{ng} \mathrm{g}^{-1}$ with a wide range (35.4-46,191.58 $\left.\mathrm{ng} \mathrm{g}^{-1}\right)$. The concentration of fluorene was found to be the highest $\left(1,606.30 \pm 251.54 \mathrm{ng} \mathrm{g}^{-1}\right)$ followed by anthracene, chrysene and phenanthrene. The $\Sigma \mathrm{PAH}$ concentration was significantly varied among months and there was no significant difference among sites at $p=0.05$. The 2-3 aromatic ring compounds accounted for $60 \%$ of the total PAHs in pellets of Mumbai coast while 4 rings and 5-6 rings compounds accounted for 26 and 14\%, respectively. The ratio of low and high molecular weight PAHs indicated that the contamination by petrogenic sources was predominant over the pyrogenic ones in plastic pellets suggesting oil pollution in coastal area of Mumbai.
\end{abstract}

Keywords: Mumbai, PAHs, plastic pellets

\section{Introduction}

Polycyclic Aromatic Hydrocarbons (PAHs) are a class of ubiquitous pollutants that are found in polluted marine areas (Karapanagioti et al., 2009) which consist of two or more fused benzene rings in various arrangements (Blumer, 1976). There are over 100 different PAH

\footnotetext{
* Correspondence: hjayasiri@yahoo.com

Tel: +94779828173

ISSN 2235-9370 Print/ISSN 2235-9362 Online (C University of Sri Jayewardenepura
} 
compounds (Perelo, 2010). A number of PAH compounds are known carcinogens (IARC, 1987) and bioaccumulate and biomagnify (WHO, 2010). These compounds originate naturally as well as anthropogenically through oil spills, incineration of waste and combustion of fossil fuels and wood. This class of organic compounds has been widely studied (Neff, 1979; McElory et al., 1989; Tolosa et al., 1996). Two types (petrogenic and pyrogenic) of anthropogenic sources of PAHs are found. The study of the PAHs in coastal marine environments is of great importance as these areas are biologically active and receive considerable pollutant input from land-based sources via coastal discharge.

Classifying beach litter into groups based on the material each piece is made up of has demonstrated that plastic litter predominates (Nakashima et al., 2011). However, once plastic debris reaches the ocean, the floating component is dispersed in various ways and strand on beaches all over the world affecting the marine environment. Further, plastic litter is composed of fragments of manufactured plastic products (user plastic) and pre-production plastic pellets (small granules $1-5 \mathrm{~mm}$ in diameter) which are raw material used for the production of many different plastic products. The environmental consequence of these organic polymers is sorption of organic pollutants on their surface (Mato et al., 2001; Endo et al., 2005; Karapanagioti \& Klontza, 2008) from the sea surface microlayer (SML) where the hydrophobic contaminants are known to be enriched (Booij \& van Drooge, 2001; Wurl \& Obbard, 2005) and then their ingestion by marine animals such as sea turtles and birds (Laist, 1997; Derraik, 2002; Mallory et al., 2006).

The high affinity of resin pellets with hydrophobic contaminants illustrates their utility as monitoring media for persistent organic pollutants in coastal waters (Mato et al., 2001). Most of the studies on chemical aspects of plastics have been carried out for organochlorine compounds such as PCBs, HCHs and DDTs (Carpenter et al., 1972; Mato et al., 2001; Endo et al., 2005; Ogata et al., 2009). However, in addition to the chlorinated compounds, some workers evaluated the PAHs in plastic pellets and fragments collected from marine environment (Rios et al., 2007; Teuten et al., 2009; Frias et al., 2010; Hirai et al., 2011; Karapanagioti et al., 2011). Fries \& Zarfl (2012) compared the sorption of several PAHs with different polarities to low density polyethylene and high density polyethylene. They found a decrease in diffusion coefficients when the molecular weight of the PAHs increases for both the plastic types indicating a hindered diffusion through the matrix as a result of a larger molecule size. Karapanagioti et al. (2010) carried out field and laboratory experiments to study the eroded plastic pellets collected from Greek beaches as monitoring tools for PAHs.

Two PAH distribution indexes -the ratio of LPAHs/HPAHs (sum of 2- and 3-ring PAHs to the sum of more than 3-ring PAHs)- and the ratio of phenanthrene to anthracene (Phen/Ant) have been used in many studies as useful tools to identify petrogenic and pyrolytic sources of PAHs in marine sediments (Budzinski et al., 1997; Baumard et al., 1998; Soclo et al., 2000; De Luca et al., 2004). The present study evaluates the extent of contamination and sources of 16 PAHs of the priority list of the U.S. Environmental Protection Agency (EPA) on beached plastic pellets in Mumbai coast. 


\section{Methods and Materials}

\subsection{Study area}

Mumbai $\left(18^{\circ} 55^{\prime} \mathrm{N}, 72^{\circ} 54^{\prime} \mathrm{E}\right)$ is the metropolitan city on the west coast of India and the capital of the State of Maharashtra. The State of Maharashtra accounts for a $653 \mathrm{~km}$ long coastline with $17 \%$ sandy beaches, many of them are lying within the Mumbai city (Kumar et al., 2006). The increase in urbanization and industrialization has led to an increase in marine discharges. The city generates $2.2 \times 10^{6} \mathrm{~m}^{3} \mathrm{~d}^{-1}$ of domestic sewage, out of which, about $2 \times 10^{6}$ $\mathrm{m}^{3} \mathrm{~d}^{-1}$ (largely untreated) enters the marine waters including creeks and bays (Zingde, 1999). Tide, currents and waves bring these pollutants to the beaches. It has a great diversity of industries in the metropolitan region. About $8 \%$ of the industries in the country are located upstream around Mumbai. A variety of industries, including refineries and petrochemical complexes, from this area release their effluents, largely untreated, into the sea. There are a number of ports wherein the ship and cargo handling activities contribute to marine pollution. This has resulted in the degradation of the coastal water quality, contamination of the adjoining beaches and seafronts (Kumar et al., 2006). The tidal range at Mumbai coast reaches a maximum value of about $5 \mathrm{~m}$ during spring tide (Unnikrishnan, 1999). Moreover, the seasonally reversing monsoon winds over the Northern Indian Ocean force a seasonally reversing circulation in the upper ocean (Shankar et al., 2002). Industrial effluents and domestic sewage from the highly developed metropolitan area of the city enter the shelf in the region. During the study, two oil spills were reported off Juhu beach in July (stranded MV Pavit on Juhu beach, $30^{\text {th }}$ June 2011) and August (sunken $M V R a k$ on $4^{\text {th }}$ August 2011; 24 nautical miles away from the coast). The area has considerable economic importance. Out of nine beaches located in Mumbai coast, four beaches namely Aksa, Versova, Juhu and Mahim, which show wide geographical coverage were selected for the study (Fig. 1).

Mumbai weather experiences very little seasonal variation due to the moderating effect of the Arabian Sea. However, it can be categorized into four seasons: summer, winter, monsoon and the withdrawal season. December to February is the winter season, March to May is summer, June to September experiences monsoon and October to December is the withdrawal season (http://www.mapsofindia.com/mumbai/mumbai-weather.html). Mumbai receives most of the rain during the monsoon season and accounts for a total rainfall of about 1,800 $\mathrm{mm}$ in a year. The Arabian Sea becomes rough and turbulent with high rising waves during the monsoon season.

\subsection{Sampling}

The field surveys were carried out on a bimonthly basis from May 2011 to March 2012 to cover all the seasons in Aksa, Versova, Juhu and Dadar beaches. The plastic pellets were picked up one by one from the sand surface using solvent-rinsed stainless tweezers or by hand along the high tide line. Around 100 pellets were collected from each beach (Endo et al., 2005). Samples were stored in amber glass vials and transported to the laboratory. Pellets were kept in desiccators to remove moisture and stored in pre-baked amber coloured glass vials at $4^{0} \mathrm{C}$ till the chemical analysis was performed (Hirai et al., 2011). 


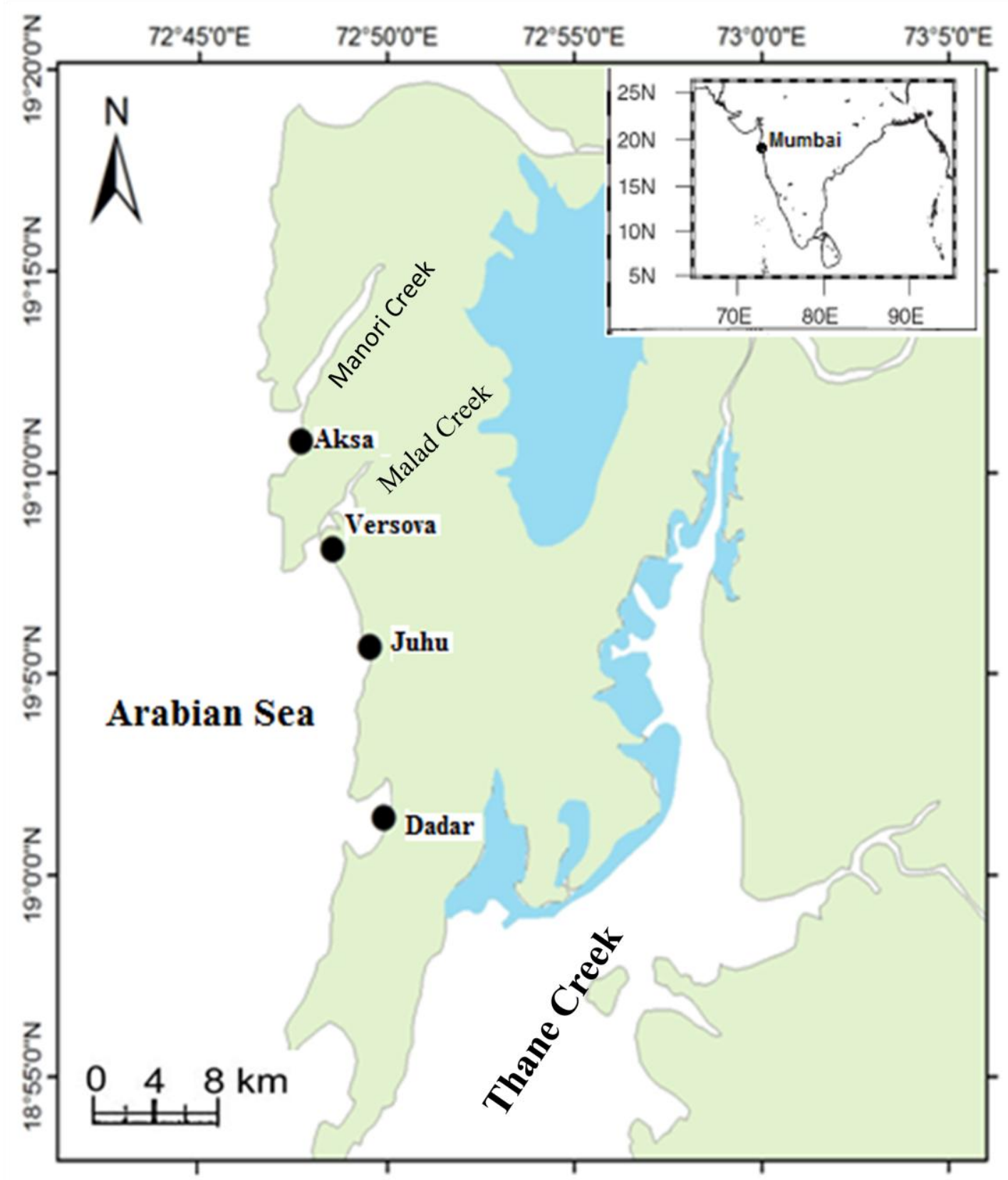

Fig.: 1. Map showing the sampling sites in Mumbai coast.

\subsection{Analysis of PAHs in plastic pellets}

The PAHs in the plastic samples were extracted and fractionated according to the method described by Ogata et al. (2009) for POPs in plastic pellets. Among the pellets, yellowing ones were selected by the naked eye for chemical analysis. The coloured or pigmented pellets were excluded from the analysis (Endo et al., 2005). The pellets were pooled in triplicate with each pool consisting of ten pellets at each site. Each pool (sample) was weighed and introduced into a 
30-ml amber vial. Approximately $15 \mathrm{ml}$ of hexane (chromatography grade, Merck) was added and shaken well, and the vial was kept in dark at room temperature for 72 hours for extraction. The extraction was repeated using fresh solvent. These sequential extracts were combined and concentrated by rotary evaporator (Superfit, India) up to approximately $0.5 \mathrm{ml}$ and introduced on to a fully activated silica gel column (18 cm x $0.5 \mathrm{~cm}$ i.d.; $100-200$ mesh silica gel from Merck). The column was conditioned using $n$-hexane. Then, the sample extract was added to the column using a combusted disposable pasture pipette and the first and second fractions were eluted with 5 $\mathrm{ml}$ and $30 \mathrm{ml}$ hexane respectively. The third fraction, containing PAHs, was eluted with $20 \mathrm{ml}$ hexane/DCM (3:1 v/v) and evaporated to $\sim 1.0 \mathrm{ml}$ by rotary evaporator and transferred into $2.0 \mathrm{ml}$ amber vials and further concentrated to $0.5 \mathrm{ml}$ by purified gentle $\mathrm{N}_{2}$ stream, and sealed in an amber vial until analyzed using gas chromatograph (GC).

\subsection{GC-MS analysis of PAHs}

The concentrated extract containing PAHs was analysed by GC coupled to a mass spectrometer (GC/MS-QP2010; Shimadzu, Japan), operating in electron impact ionization mode (70 eV). Compound separation was achieved using Rxi ${ }^{\circledR}-5$ Sil MS column of $30 \mathrm{~m} \times 0.25 \mathrm{~mm}$ i.d. with $0.25 \mu \mathrm{m}$ film thickness (Restek, USA). The temperature programme was as follows: from $100^{\circ} \mathrm{C}$ (holding time $4 \mathrm{~min}$ ) to $300^{\circ} \mathrm{C}$ at $7.5^{\circ} \mathrm{C} \mathrm{min}^{-1}$, keeping the final temperature for 15 minutes. Injection was in split mode. Helium was used as the carrier gas at a flow of $1.5 \mathrm{ml} \mathrm{min}^{-1}$. The transfer line and the ion source temperatures were set at 280 and $230^{\circ} \mathrm{C}$, respectively. The total run time was 45 minutes and the injected volume was $1 \mu 1$. The electron impact (EI) mass spectra were acquired in the full-scan mode. The identification and quantification of analytes were carried out with GC/MS Solution software (Shimadzu, Japan) using external standard methods.

Sixteen PAHs considered to be of primary environmental concern according to USEPA were analysed in this study. These are naphthalene (Naph), acenaphthylene (Acy), acenaphthene (Ace), fluorene (Flu), phenanthrene (Phe), anthracene (Ant), fluoranthene (Flut), pyrene (Pyr), benzo(a)anthracene (B[a]A), chrysene (Chr), benzo(b)fluoranthene (B[b]F), benzo(k) fluoranthene $(\mathrm{B}[\mathrm{k}] \mathrm{F})$, benzo(a)pyrene $(\mathrm{B}[\mathrm{a}] \mathrm{P})$, indeno(1,2,3-cd)pyrene $(\mathrm{I}[\mathrm{cd}] \mathrm{P})$, dibenzo(a,h) anthracene $(\mathrm{D}[\mathrm{ah}] \mathrm{A})$ and benzo(g,h,i)perylene $(\mathrm{B}[\mathrm{ghi}] \mathrm{P})$. PAH standard solution $\left(10 \mathrm{ng} \mu \mathrm{l}^{-1}\right)$ in cyclohexane was purchased from Sigma-Aldrich (Germany).

\subsection{Method validation}

Five samples containing ten pellets each were spiked with deuterated PAH surrogate standards of Naphthalene-d8, Phenanthrene-d10 and $p$-Terphenyl-d14, and analysed to assess the overall procedural recovery; the recovery varied from $84.46 \%$ to $87.40 \%$.

\subsection{Statistical analysis}

All statistical comparisons were performed using SPSS software (Version 16). Analysis of variance was carried out for the effect of month, beach and their interactions at the significance level of $p<0.05$ for the $\Sigma$ PAHs, $\Sigma$ LPAHs and $\Sigma$ HPAHs. For significant effects, the mean separation was carried out by Duncan grouping at $p=0.05$. Cluster analysis was performed for 
PAH compounds in plastic pellets and sediment to examine the underlying relationships between the compounds.

\section{Results}

The mean concentration of sum of $16 \mathrm{PAH}$ compounds ( $\Sigma \mathrm{PAHs}$ ) was extremely high $\left(9202.30 \pm 114.89 \mathrm{ng} \mathrm{g}^{-1}\right)$ with a wide range (35.4-46191.58 $\left.\mathrm{ng} \mathrm{g}^{-1}\right)$ in plastic pellets. The concentration of Flu was found to be the highest $\left(1606.30 \pm 251.54 \mathrm{ng} \mathrm{g}^{-1}\right)$ followed by Ant, Chr and Phe in plastic pellets. Acy showed the lowest concentration of $49.01 \pm 21.21 \mathrm{ng} \mathrm{g}^{-1}$ (n.d.$926.03 \mathrm{ng} \mathrm{g}^{-1}$ ). However, Phe and Ant were found as the most dominant PAH with $95.83 \%$ detection followed by Naph, Ace, Flu, Chr, Pyr, Flut, B[a]A and D[ah]A with more than 50\% frequency of detection. The least detected compounds were Acy, B[k]F, B[b]F and D[ah]A (Fig. 2). The concentration of 16 individual PAHs varied largely among the 72 samples ranging from undetectable levels to $16,936.37 \mathrm{ng} \mathrm{g}^{-1}$.

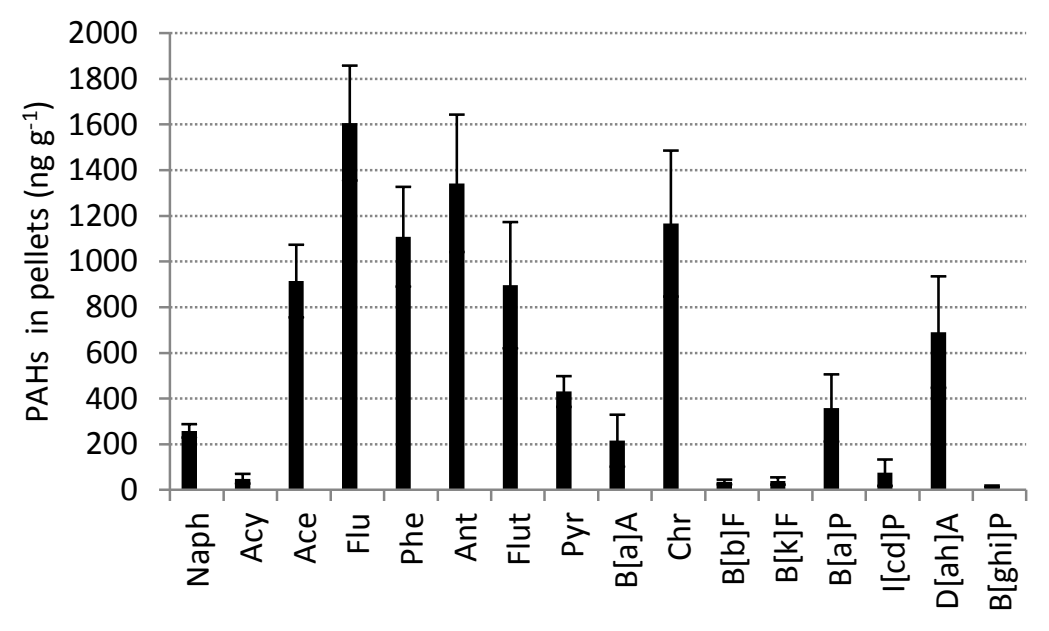

Fig. 2: PAHs concentration (mean $\pm S E)$ in plastic pellets $(n=72)$.

Two-way ANOVA revealed that the temporal variation was significant for $\Sigma$ PAHs and $\Sigma$ LPAHs, while spatial variation was significant for $\Sigma$ HPAHs in plastic pellets. Though, there was no spatial variation of $\Sigma$ LPAHs, the interaction of the months and sites was significant at $p=0.05$ (Table 1). The $\Sigma$ PAHs accumulation was significantly higher in July and September than that of November, January and March at $p=0.05$. The $\Sigma$ LPAH fraction was significantly higher in July and September than those of the other months while that of May was intermediate (Fig. 3a). Among the sites, significantly higher $\Sigma$ LPAHs were found in Versova $\left(7749.3 \pm 2821.82 \mathrm{ng} \mathrm{g}^{-1}\right)$ than at the other sites in pellets (Fig. 3b). 
Jayasiri, Purushothaman \&Vennila/Journal of Tropical Forestry and Environment Vol. 4, No 01 (2014) 67-79

Table 1: Results of two-way ANOVA for $\Sigma P A H s, \Sigma L P A H$ s and ( $\Sigma H P A H s)$ in plastic pellets $(n=72)$.

\begin{tabular}{|c|c|c|c|c|c|c|c|}
\hline \multirow[t]{3}{*}{ Source } & \multicolumn{7}{|c|}{ Plastic pellets } \\
\hline & \multirow[t]{2}{*}{$\mathrm{DF}$} & \multicolumn{2}{|c|}{$\Sigma$ PAHs } & \multicolumn{2}{|c|}{$\Sigma$ LPAH } & \multicolumn{2}{|c|}{$\Sigma \mathrm{HPAHs}$} \\
\hline & & MS & $\mathrm{F}$ & MS & $\mathrm{F}$ & MS & $\mathrm{F}$ \\
\hline Month & 5 & $48.56 \times 10^{7}$ & $8.30 *$ & $27.60 \times 10^{7}$ & $16.52 *$ & $68.48 \times 10^{6}$ & 1.56 \\
\hline Beach & 3 & $99.06 \times 10^{6}$ & 1.69 & $24.00 \times 10^{6}$ & 1.48 & $11.99 \times 10^{7}$ & $2.73^{*}$ \\
\hline Monthxbeach & 15 & $77.84 \times 10^{6}$ & 1.33 & $39.27 \times 10^{6}$ & $2.35^{*}$ & $38.19 \times 10^{6}$ & 0.87 \\
\hline Error & 48 & $58.50 \times 10^{6}$ & & $16.71 \times 10^{6}$ & & $43.92 \times 10^{6}$ & \\
\hline
\end{tabular}

Significantly different $(p<0.05)$

Overall mean revealed that LPAHs (2-3 ring compounds) were predominant over HPAHs in beach plastic pellets of Mumbai with $60 \%$ of total PAHs (Fig. 4). The ratio of LPAHs to HPAHs was calculated bimonthly and which ranged from 1.07 (November) to 6.34 (July) showing the predominance of petrogenic origin PAH compounds over pyrogenic ones in plastic pellets. The dendrogram based on cluster analysis also showed the separation of petrogenic compounds and mixed sources of petrogenic and pyrogenic compound in plastic pellets (Fig. 5).

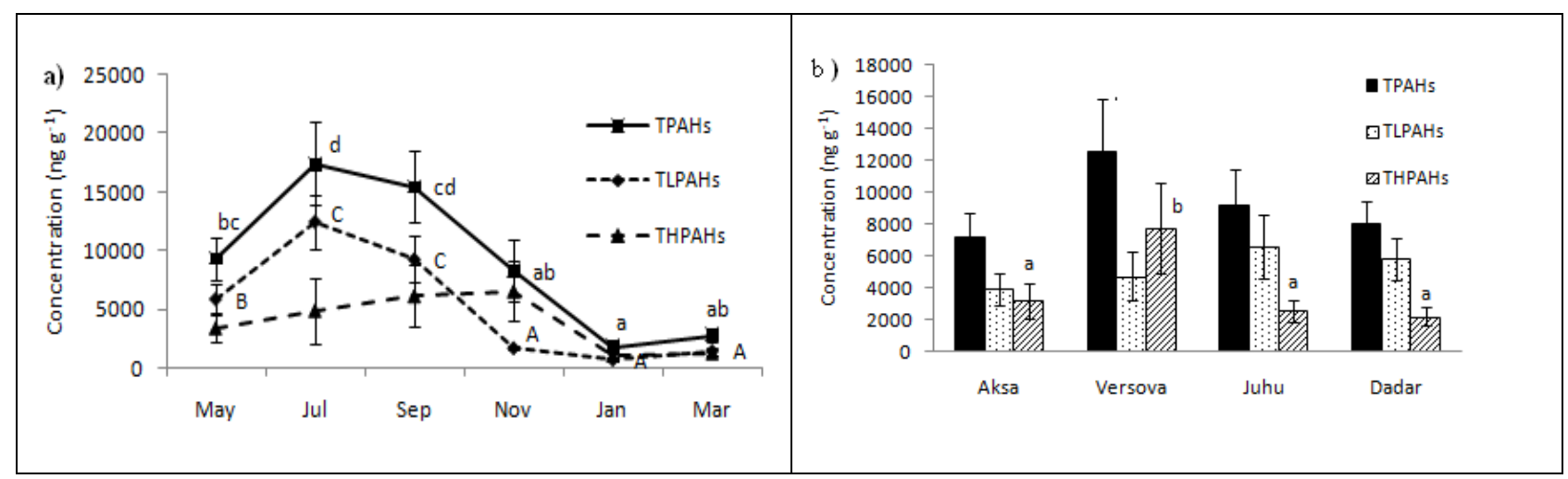

Fig. 3. Variation of $\Sigma P A H s$ (TPAHs), $\Sigma L P A H s$ (TLPAHs) and $\Sigma H P A H s$ (THPAHs) a) bimonthly in plastic pellets (the data points with different letters in lowercase and uppercase represent the significant difference for $\Sigma P A H$ s and $\Sigma L P A H$ s respectively at $p=0.05)$, (b) Beach-wise variation of (bars with different letters represent the significant difference for of $\Sigma H P A H s$ at $p=0.05$ ).

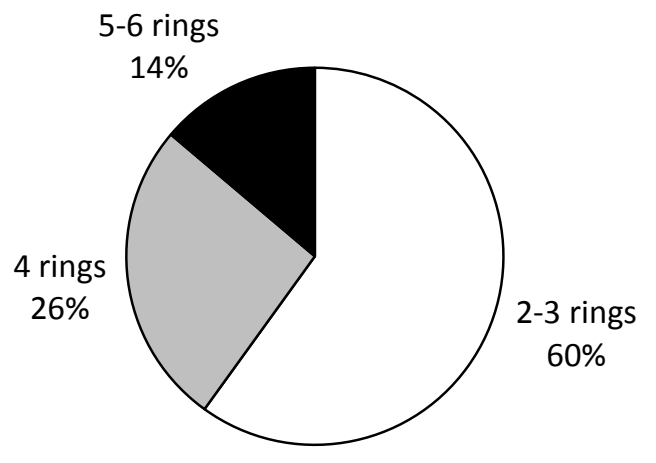

Fig. 4: Overall relative compositions of PAHs according to ring number $(n=72)$ in plastic pellets. 


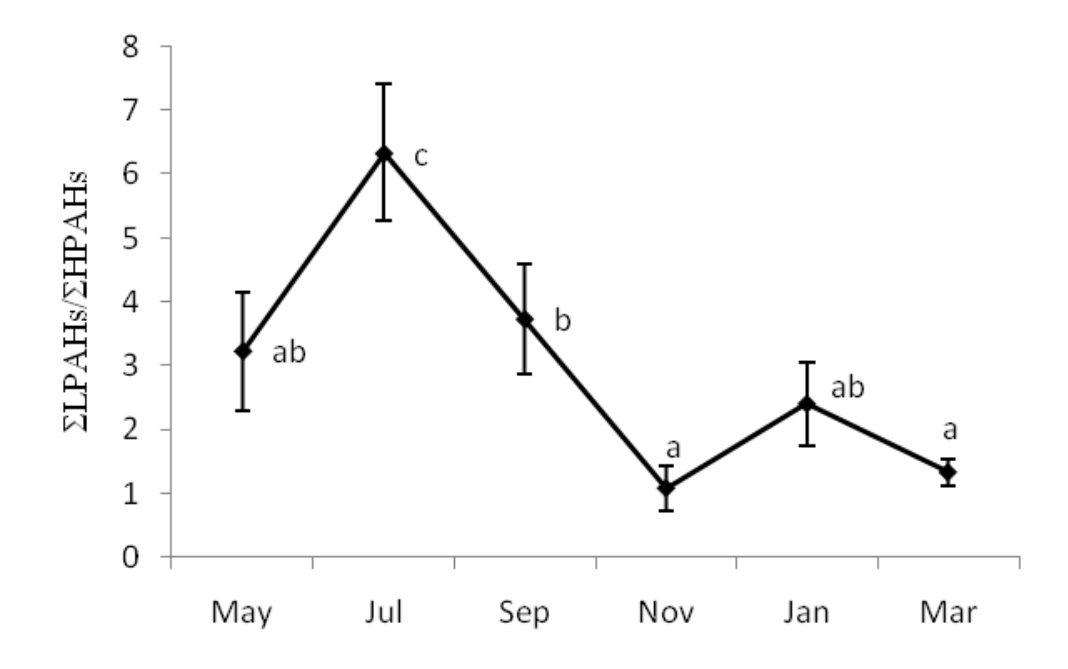

Fig. 5. Bimonthly variation of $\frac{\sum \text { LPAHs }}{\sum \boldsymbol{H P A H S}}$ during the study in plastic pellets.

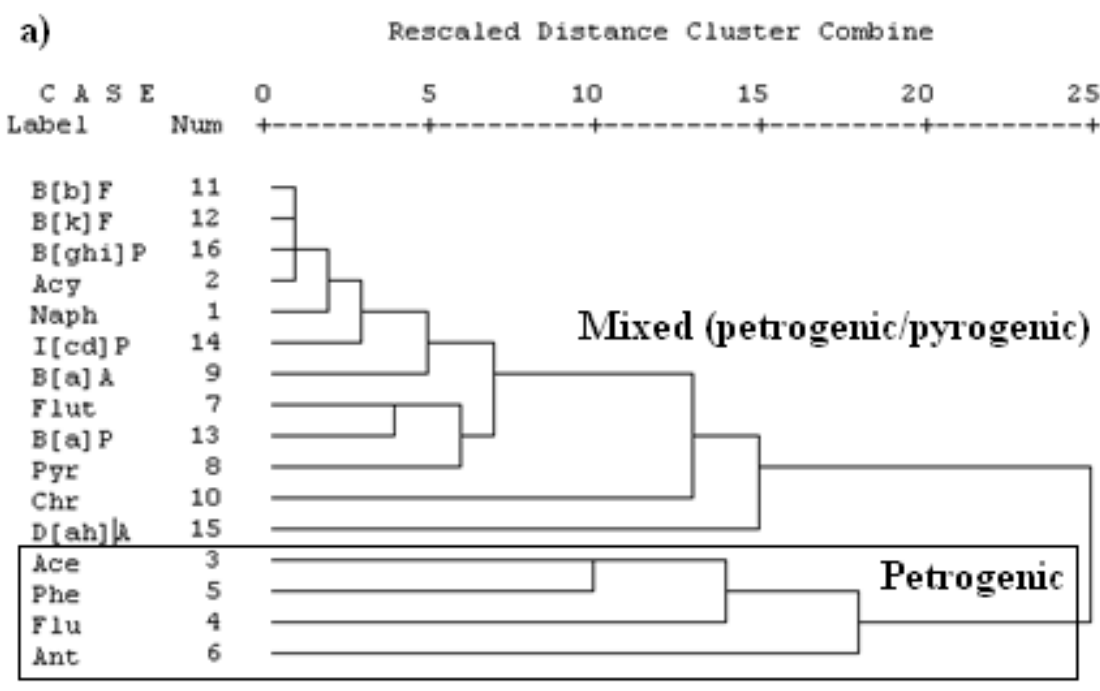

Fig. 6: Dendrogram based on complete linkage for PAH compound in plastic pellets.

\section{Discussion}

Marine pollution comprising industrial and domestic loads as well as hydrocarbons and tar deposits leads to the deterioration of most of the beaches and coastal waters around Mumbai. The 16 PAHs in the priority list of the USEPA were evaluated in plastic pellets during the study and the results illustrated substantially higher mean $\Sigma \mathrm{PAH}$ concentration in the pellets of Mumbai beaches when compared to the other studies (Mato et al., 2001; Karapanagioti et al., 2011). The highest range reported is 39-12,000 $\mathrm{ng} \mathrm{g}^{-1}$ in Los Angeles industrial area by Rios et al. (2007). 
Though different authors found different ranges, some have been reported as median and not the mean.

The atmospheric transport of PAH from heavy urbanization (traffic of trucks and cars) is the most probable pyrogenic source of the PAHs (Sanderson et al., 2004; Cachier et al., 2005). In this study, except Acy, other low-molecular weight compounds had high mean concentrations and predominated over the high-molecular weight compounds suggesting that the sources of these compounds are petroleum hydrocarbons in plastic pellets due to oil pollution in the area. The PAHs distribution index calculated for plastic pellets also confirmed the oil pollution. In the areas contaminated by petroleum, the SML can be enriched by a factor of 1,000 (Hardy et al., 1987) and up to 2,000 (Guitart et al., 2008) with hydrocarbons as a result of slick formation. This suggests oil pollution in coastal sea off Mumbai.

Liquid petroleum is a complex mixture of tens of thousands of compounds, in which various hydrocarbons are the most abundant classes, usually accounting for $75 \%$ of the total oil composition (OSPAR, 2004). A typical crude oil may contain 0.2 to $0.7 \%$ total PAHs, with fourto six-ring PAHs present at low or trace concentrations (NRC, 2003). During the study, two oil spills were reported in July and August off Juhu beach. Both the incidents occurred during the monsoon period and the oil might have spread in coastal area by wind-driven surface currents affecting all the studied beaches with different levels of accumulation. Further, oil slicks and tar were observed in some pellets on Juhu, Versova and Aska beaches after the oil spills. The risk of major oil spills occurring along the west coast of India is considerably higher now as there has been a significant increase in all types of maritime trade (Sivadas et al., 2008).

The offshore oil exploration in the Bombay High region, Mumbai harbour, fishing activities and land-based sources may increase the level of petroleum hydrocarbons in the coastal sea off Mumbai. Therefore, high concentrations of petrogenic PAHs can be expected.

The EPAHs varied temporally showing significantly high concentration in July and September in pellets and this can be correlated with the two oil spills that occurred in July and August. The low $\mathrm{PPAHs}$ in January and March indicate that the pellets collected during this period were fresh and there was no impact from oil spills. However, the significantly high concentration of $\Sigma$ PAHs during July in plastic pellets reveals that plastics have high affinity to sorb PAHs than sediment as suggested by Teuten et al. (2007). A similar temporal trend was observed for the $\Sigma$ LPAHs with significantly higher concentration in July and September than the other months which confirms the impact of oil spills on LPAHs that sorb to plastic pellets.

Further, the $\Sigma$ HPAHs were significantly high in pellets collected from Versova beach. Dadar and Versova are located in a semi-enclosed area geomorphologically with restricted water exchange. Thus, the high PAH accumulation can be expected in these sites. Further, Versova had significantly higher organic carbon than other sites (Jayasiri, 2013) and receives waste water via Malad Creek indicating high pollution. Mahim Bay, where Dadar is located, receives large quantities of industrial and domestic waste via Mahim Creek resulting in high PAH pollution. Further, sewage from slums and fishing activities also might contribute to the high PAH contamination in Versova. Furthermore, Versova fishing boat anchorage and ferry service across the Malad Creek also could be a significant source for combusted fossil fuel which is a significant source for high-molecular weight PAH concentration in pellets from Versova beach. Moreover, only a few studies relevant to PAHs in plastic pellets have been carried out and the 
$\Sigma$ PAHs reported only spatially in the regional scale. The high percentage of plastic pellets has been reported in sediment from Versova beach followed by Dadar beach (Jayasiri, 2013).

The compositional patterns of PAHs may provide information about petrogenic or pyrogenic sources. PAHs may originate from pyrolytic sources including the natural and anthropogenic combustion of organic matter (e.g., forest fires, domestic coal or wood combustion and car exhausts) and from petrogenic sources (e.g., present in subsoil, oil spills) (Sun et al., 2008). Studies have shown that high $\Sigma$ LPAHs/ $\Sigma$ HPAHs ratios $(>1)$ often indicate that PAHs with petrogenic sources predominate while low ratios $(<1)$ suggest the dominance of PAHs of pyrolytic origin (Budzinski et al., 1997). Phe and Ant were found as the most dominant PAHs in the present study in pellets showing predominance of petrogenic PAHs. Hirai et al. (2011) also reported the predominance of petrogenic PAHs with a ratio of $0.32 \pm 0.49$ (HPAHs/LPAHs) in plastic fragments. While, Rios et al. (2007) found a ratio (LPAHs/HPAHs) of 0.23, indicating that combusted fossil fuels are the principal source of PAHs in plastic pellets. Crude oil $(n=7)$ has a HPAHs/LPAHs of $0.19 \pm 0.07$, whereas wood combustion products and coal combustion products have a HPAHs/LPAHs of $2.17 \pm 1.34$ and 6.99 \pm 9.92 , respectively (Saha et al., 2009).

Beached resin pellets can be used as a tool to monitor PAHs in coastal waters. The increasing abundance of plastic debris allows marine organisms to mistake more plastic for their natural food and ingest more plastics as they feed. These plastics are important point-sources carrying POPs including PAHs (Thompson et al., 2009). It is not only the initial organism that ingests the plastics that may be affected by the POPs, but also the organisms within its food web.

\section{Conclusion}

The sorption of PAHs is substantially higher in plastics due to sorbent properties. Further, PAH in plastic pellets confirmed that the petrogenic sources were predominant over pyrogenic sources indicating oil pollution in the Mumbai coastal region. The spatial variation closely related with geomorphology of the area and point sources of domestic and industrial waste water. Temporal variation was association with weather pattern especially the monsoon.

\section{Acknowledgments}

The first author acknowledges the Sri Lanka Council of Agricultural Research Policy and National Aquatic Resources Research Development Agency, Sri Lanka for financial and administrative arrangements to carry out this research at Central Institute of Fisheries Education, Mumbai, India. Director, CIFE, India is greatly acknowledged for the facilities provided during the study.

\section{References}

Baumard, P., Budzinski, H., Garrigues, P., 1998. Polycyclic aromatic hydrocarbons in sediments and mussels of the western Mediterranean Sea. Environmental Toxicology \& Chemistry, 17:765-776.

Blumer, M., 1976. Polycyclic aromatic compounds in nature. Scientific American, 234:35-45. 
Booij, K., van Drooge, B.L., 2001. Polychlorinated biphenyls and hexachlorobenzene in atmosphere, sea-surface microlayer and water measured with semipermeable membrane devices (SPMDs). Chemosphere, 44:91-98.

Budzinski, H., Jones, I., Bellocq, J., Pierrad, C., Garrigues, P., 1997. Evaluation of sediment contamination by polycyclic aromatic hydrocarbons in the Gironde estuary. Marine Chemistry, 58:85-97.

Cachier, H., Aulagnier, F., Sarda, R., Gautier, F., Masclet, P., Besombes J.L., et al., 2005. Aerosol studies during the ESCOMPTE experiment: An overview. Atmospheric Research, 74:547-563.

Carpenter, E.J., Anderson, S.J., Harvey, G.R., Miklas, H.P., Peck, B.B., 1972. Polystyrene particles in coastal waters. Science, 178:749-750.

De Luca, G., Futonio, A., Leardo, R., Micera, G., Panzanelli, A., Piu, P.C., Sanna, G., 2004. Polycyclic aromatic hydrocarbons assessment in the sediments of the Porto Torre Harbor (Northern Sardinia, Italy). Marine Chemistry, 86:15-32.

Derraik, J.G.B., 2002. The pollution of the marine environment by plastic debris: A review. Marine Pollution Bulletin, 44:842-852.

Endo, S., Takizawa, R., Okuda, K., Takada, H., Chiba, K., Kanehiro, H., Ogid, H., Yamashita, R., Takeshi, D., 2005. Concentration of polychlorinated biphenyls (PCBs) in beached resin pellets: Variability among individual particles and regional differences. Marine Pollution Bulletin, 50:1103-1114.

Frias, J.P.G.L., Martins, J., Sobral, P., 2011. Research in plastic marine debris in mainland Portugal. Journal of Integrated Coastal Zone Management, 11(1):145-148.

Fries, E, Zarfl, C., 2012. Sorption of polycyclic aromatic hydrocarbons (PAHs) to low and high density polyethylene (PE). Environmental Science \& Pollution Research International, 19(4):1296-304.

Guitart, C., Frickers, P., Horrillo-Caraballo, J., Law, R.J., Readman, J.W., 2008. Characterization of sea surface chemical contamination after shipping accidents. Environmental Science and Technology, 42:2275-2282.

Hirai, H., Takada, H., Ogata, Y., Yamashita, R., Mizukawa, K., Saha, M., Kwan, C., Moore, C., Gray, H., Laursen, D., Zettler, E.R., Farrington, J.W., Reddy, C.M., Peacock, E.E., Ward, M.W., 2011. Organic micropollutants in marine plastics debris from the open ocean and remote and urban beaches. Marine Pollution Bulletin, 62(8):1683-1692.

Hardy, J.T., Crecelius, E.A., Antrim, L.D., Broadhurst, V.L., Apts, C.W., Gurtisem, J.M., Fortman, T.J., 1987. The sea-surface microlayer of Puget Sound: Part II. Concentrations of contaminants and relation to toxicity. Marine Environment Research, 23:251-271.

IARC, 1987. IARC Monographs on the Evaluation of Carcinogenic Risks to Humans, Supplement 7, Overall Evaluations of Carcinogenicity: An Updating of IARC Monographs Volumes 1 to 42. IARC, Lyon, France.

Jayasiri, H.B., 2013. Assessment of persistent organic pollutants in plastic debris and sediment in Mumbai beaches. Ph.D. Thesis, Central Institute of Fisheries Education, Mumbai: India.

Karapanagioti, H.K., Siavalas, G., Kalaitzidis, S., Papatheodorou, G., Christanis, K., 2009. Distribution of polycyclic aromatic hydrocarbons (PAHs) in the Gulf of Aliveri, Central Greece, in: Proceedings of the 9th National Greek Symposium on Oceanography and Fishery: Patras, 1. pp.251-255. 
Karapanagioti, H.K., Klontza, I., 2008. Testing phenanthrene distribution properties of virgin plastic pellets and plastic eroded pellets found on Lesvos Island beaches (Greece). Marine Environment Research, 65:283-290.

Karapanagioti, H.K., Endo, S., Ogata, Y., Takada, H., 2011. Diffuse pollution by persistent organic pollutants as measured in plastic pellets sampled from various beaches in Greece. Marine Pollution Bulletin, 62:312-317.

Karapanagioti, H.K., Klontza, I., 2007. Investigating the properties of plastic resin pellets found in the coastal areas of Lesvos Island. Global Nest Journal, 9:71-76.

Kumar, A., Dayal, P., Shukla, G., Singh, G., Joseph, P.E., 2006. DDT and HCH residue load in mother's breast milk: A survey of lactating mothers from remote villages in Agra region. Environment International, 32(2):248-251.

Laist, D.W., 1987. Overview of the biological effects of lost and discarded plastic debris in the marine environment. Marine Pollution Bulletin, 18:319-326.

Mallory, M.L., Robertson G.J., Moenting, A., 2006. Marine plastic debris in northern fulmars from Davis Strait, Nunavut, Canada. Marine Pollution Bulletin, 52:800-815.

Mato, Y., Isobe, T., Takada, H., Kanehiro, H., Ohtake, C., Kaminuma, T., 2001. Plastic resin pellets as a transport medium for toxic chemicals in the marine environment. Environmental Science \& Technology, 35:319-324.

McElory, A.E., Farrington, J.W., Teal, J.M., 1989. Bioavailability of polycyclic aromatic hydrocarbons in aquatic environment. in: Varanasi, U. (Eds), Metabolism of polycyclic aromatic hydrocarbons in the aquatic environment. Boca Raton, FL: CRC Press, pp. 1-40.

Nakashima, E., Isobe, A., Magome, S., Kako, S., Noriko, D., 2011. Using aerial photography and in situ measurements to estimate the quantity of macro-litter on beaches. Marine Pollution Bulletin, 62:762-769.

Neff, J. M., 1979. Polycyclic aromatic hydrocarbons in the aquatic environment: Sources, fates and biological effects. Barking, UK: Applied Science Publishers.

NRC, 2003. Committee on oil in the Sea: Inputs, Fates, and Effects. National Academy of Sciences, Washington, DC.

Ogata, Y., Takada, H., Mizukawa, K., Hirai, H., Iwasa, S., Endo, S., et al., 2009. International Pellet Watch: Global monitoring of persistent organic pollutants (POPs) in coastal waters. 1. Initial phase data on PCBs, DDTs and HCHs. Marine Pollution Bulletin, 58:1437-1446.

OSPAR, 2004. Report of workshop on the evaluation and update of background reference concentrations (B/RCs) and ecotoxicological assessment criteria (EACs) and how these assessment tools should be used in assessing contaminants in water, sediment and biota. Hague, Netherlands.

Perelo, L.W., 2010. Review: In situ and bioremediation of organic pollutants in aquatic sediments. Journal of Hazardous Materials, 177:81-89.

Rios, L.M., Moore, C., Jones, P.R., 2007. Persistent organic pollutants carried by synthetic polymers in the ocean environment. Marine Pollution Bulletin, 54:1230-1237.

Saha, M., Togo, A., Mizukawa, K., Murakami, M., Takada, H., Zakaria, M.P., et al., 2009. Sources of sedimentary PAHs in tropical Asian waters: Differentiation between pyrogenic and petrogenic sources by alkyl homolog abundance. Marine Pollution Bulletin, 58(2):189-200. 
Sanderson, E.G., Raqbi, A., Vyskocil, A., Farant, J.P., 2004. Comparison of particulate polycyclic aromatic hydrocarbon profiles in different regions of Canada. Atmospheric Environment, 38:3417-3429.

Shankar, D., Vinayachandran, P.N., Unnikrishnan, A.S., 2002. The monsoon currents in the north Indian Ocean. Progress in Oceanography, 52:63-120.

Sivadas, S., Gregory, A., Ingole, B., 2008. How vulnerable is the Indian coast to oil spills? Impact of MV Ocean Seraya oil spill. Current Science, 95(4):504-512.

Soclo, H.H., Garrigues, P., Ewald, M., 2000. Origin of polycyclic aromatic hydrocarbons (PAHs) in coastal marine sediments: Case studies in Cotonou (Benin) and Aquitaine (France) areas. Marine Pollution Bulletin, 40:387-396.

Sun, J. -H., Wang, G. -L., Chai, Y., Zhang, G., Li, J., Feng, J., 2008. Distribution of polycyclic aromatic hydrocarbons (PAHs) in Henan Reach of the Yellow River, Middle China. Ecotoxicology \& Environment Safety, 72:1614-1624.

Teuten, E.L., Rowland, S.J., Galloway, T.S., Thompson, R.C., 2007. Potential for plastics to transport hydrophobic contaminants. Environmental Science \& Technology, 41:77597764.

Teuten, L., Saquing J.M., Knappe, D.R.U., Barlaz, M.A., Jonsson, S., Björn, A., et al., 2009. Transport and release of chemicals from plastics to the environment and to wildlife. Philosophical Transactions of the Royal Society of London, Series B, 364:2027-2045.

Thompson, R.C., Swan, S.H., Moore, C.J., vom Saal, F.S., 2009. Our plastic age. Philosophical Transactions of the Royal Society of London, Series B, 364:1973-1976.

Tolosa, I., Bayona, J.M., Albaiges, J., 1995. Spatial and temporal distribution, fluxes and budgets of organochlorinated compounds in Northwest Mediterranean sediments. Environmental Science \& Technology, 29:2519-2527.

Unnikrishnan, A.S., Shetye, S.R., Michael, G.S., 1999. Tidal propagation in the Gulf of Khambhat, Bombay High and surrounding areas. Proceedings of Indian Academy of Science, 108(3), 155-177.

WHO, 2010. Persistent organic pollutants: Impact on child health. Switzerland: Geneva.

Wurl, O., Obbard, J.P., 2005. Chlorinated pesticides and PCBs in the sea-surface microlayer and seawater samples of Singapore. Marine Pollution Bulletin, 50:1233-1243.

Zingde, M. D., 1999. Marine pollution: What are we heading for? in: Ocean science: Trends and future directions. Indian National Science Academy, New Delhi, pp. 229-246. 